\title{
Necropolítica, Biopolítica Perversa e a Subversão do Cuidado Integrativo para Presos
}

\author{
Marisangela Spolaôr Lena ${ }^{1}$ \\ ${ }^{1}$ Universidade Federal do Rio Grande do Sul, RS, Brasil.
}

\author{
Tonantzin Ribeiro Gonçalves ${ }^{2}$ \\ ${ }^{2}$ Universidade do Vale do Rio dos Sinos, RS, Brasil.
}

Resumo: As prisões brasileiras são conhecidas pelas condições indignas à sobrevivência e pela violência, devido às quais os indivíduos são reduzidos à condição de vidas nuas. Porém, em Porto Velho, Rondônia, a Associação Cultural de Desenvolvimento do Apenado e Egresso (Acuda) oferta cuidados integrativos aos presos; diante disso, este artigo objetiva analisar como as estratégias biopolíticas e necropolíticas coexistiam com ações de subversão dessa lógica na relação entre instituições e Estado. O estudo se baseou em uma etnografia, envolvendo observações participantes e entrevistas em profundidade com os frequentadores, funcionários e diretores da Acuda. A análise, ancorada em leituras pós-estruturalistas, discute a articulação entre estratégias necropolíticas e biopolíticas perversas protagonizadas pelo Estado, que promove tanto a morte quanto a vida, ainda que precária. Ao mesmo tempo, a interpenetração entre essas diferentes instâncias sustentava, paradoxalmente, linhas de resistência consoantes à insistência dos presos em viver suas vidas possíveis.

Palavras-chave: Necropolítica, Biopolítica, Cuidados integrativos, Presos, Saúde prisional.

\section{Necropolitics, Perverse Biopolitics, and the Subversion of the Integrative Care for Prisoners}

\begin{abstract}
Brazilian prisons are known for undignified survival conditions and for violence, which reduce individuals to a baren life. However, in Porto Velho, Rondônia, the Cultural Association for Prisoner and Egress Development (ACUDA) offers integrative care to prisoners; in this context, this article aims to analyze how biopolitical and necropolitical strategies coexisted with actions to subvert this logic in the relation between institutions and the State. The study was based on an ethnography, involving participant observations and in-depth interviews with ACUDA attendees, staff, and directors. The analysis, based on poststructuralist assumptions, discusses the articulation between necropolitical and perverse biopolitical strategies carried out by the State, which promote both death and life, even if precarious. At the same time, the interpenetration between these different instances paradoxically held lines of resistance as the prisoners insisted on living their possible lives.
\end{abstract}

Keywords: Necropolitics, Biopolitics, Integrative care, Prisoners, Prison health.

\section{Necropolítica, Biopolítica Perversa y Subversión de la Atención Integral a los Prisioneros}

Resumen: Las cárceles brasileñas son conocidas por condiciones indignas a la supervivencia y por la violencia, donde las personas se encuentran reducidas a la condición de nudas vidas. 
Sin embargo, considerando que en Porto Velho, en Rondônia (Brasil), la Asociación Cultural para el Desarrollo de Reclusos y Egresos (Acuda) ofrece atención integral a los prisioneros; el propósito de este artículo es analizar cómo las estrategias biopolíticas y necropolíticas coexisten con acciones para subvertir esta lógica en la relación entre las instituciones y el Estado. El estudio se basó en una etnografía, que incluyó a observaciones de los participantes y entrevistas en profundidad con los asistentes, empleados y directores de Acuda. El análisis basado en lecturas posestructuralistas discute la articulación entre las estrategias necropolíticas y biopolíticas perversas dirigidas por el Estado, las cuales promueven la muerte y la vida aunque de manera precaria. Al mismo tiempo, estas diferentes instancias mantienen, paradójicamente, líneas de resistencia de acuerdo con la insistencia de los prisioneros en vivir sus posibles vidas.

Palabras clave: Necropolítica, Biopolítica, Atención integral, Prisioneros, Prisión de salud.

\section{Introdução}

O Brasil é o quarto país que mais prende no mundo e em 2016 tinha mais de 720 mil presos e um déficit de 350 mil vagas no sistema prisional (Ministério da Justiça e Segurança Pública [MJSP], 2017). As prisões brasileiras têm sido consideradas os piores locais do mundo para se viver, dado que há relatos de falta de recursos básicos, de assistência jurídica e à saúde, a despeito das leis e políticas voltadas a assistir essa população (Adorno, 1991; Barcellos, 2010; Minayo \& Constantino, 2015). Somam-se a isso as iniquidades inaceitáveis representadas pelo perfil dos presos brasileiros, a maioria homens jovens, negros e pardos, com baixa escolaridade e renda (Minayo \& Constantino, 2015). Além de comporem a maioria da população prisional, os negros são, também, os que mais morrem. O Atlas da violência 2019 (Instituto de Pesquisa Econômica Aplicada [Ipea] \& Fórum Brasileiro de Segurança Pública [FBSP], 2019) revela que a cada 100 pessoas assassinadas, 71 são negras, e que negros têm $23,5 \%$ mais chances de serem assassinados em relação a brasileiros de outras raças, já descontado o efeito da idade, escolaridade, sexo, estado civil e bairro de residência.

Para Wacquant (2008), os guetos, que funcionavam como "prisões sociais", foram substituídos pelas prisões, a fim de armazenar a mão de obra marginalizada pelas transições econômicas. Assim, a ideia da prisão como uma instituição ressocializadora é substituída pela de "armazém de dejetos humanos do mercado" (Wacquant, 2007, p. 126). Similarmente, também as políticas públicas de assistência à população prisional não têm se efetivado, o que viola os direitos das pessoas presas que se encontram sob tutela do Estado.

Nesse sentido, Foucault discute sobre os dispositivos de poder e as diferentes formas de controlar os corpos e a vida da população. De uma forma de poder disciplinar voltada para o controle individual dos corpos, que tinha na prisão moderna seu mais eloquente exemplo, passa-se a uma forma de poder exercida coletivamente, por meio das estratégias da biopolítica (Foucault, 2005). Nessas circunstâncias, conforme Foucault (2005), intervém o racismo de Estado, dividindo a população em grupos e introduzindo um corte entre quem deve viver e quem deve morrer. Como em uma guerra, quanto mais se faz morrer, mais se vive. Para viver é necessário massacrar os inimigos, exterminando biologicamente aqueles que são considerados pertencentes a uma raça inferior. Porém, o Estado, na sua função assassina, só pode funcionar por meio dos mecanismos do biopoder.

Para Agamben (2007b), os presos, considerados vidas indignas de serem vividas, são deixados para morrer por meio das estratégias da biopolítica. De acordo com o autor, essa seria uma configuração contemporânea do poder do soberano, exercido sobre o direito à vida, justificada pelo desenvolvimento e segurança da nação. No campo da biopolítica, a soberania refere-se ao exercício do poder de um grupo sobre outro, tendo em vista o que é forjado como racismo de Estado, demarcando vidas autênticas e vidas nuas, sendo as últimas privadas de valor político (Agamben, 2007b). Considerando as condições de vida dos presos brasileiros, percebe-se que elas estão situadas dentro daquilo que Mbembe (2018) definiu como necropolítica, ou seja, estratégias do Estado para fazer morrer.

Conforme Bello Ramírez e Bello Gallego (2016), Mbembe, ao trazer a categoria de necropolítica, retoma e reelabora a biopolítica foucaultiana, a partir de experiências coloniais que foram constituídas a partir da violência e do terror. Para Mbembe, o racismo não surge no século XVIII como uma experiência 
intraeuropeia, mas existe desde as primeiras experiências coloniais que são fundadas na escravidão e no genocídio de indígenas na África e nas Américas. Nessa direção, Pelbart (2018) afirma

. . que a política seja declinada como necropolítica, como política de extermínio, diz algo da sobrevivência da matriz colonial no contexto contemporâneo. Como se perpetuássemos a convicção escravocrata de que um negro perambulando solto só pode ser um foragido da senzala - um bandido deve ser morto, sempre! (Pelbart, 2018, p. 16).

Em contraponto às estratégias necropolíticas e à extrema desassistência e violência nas prisões brasileiras, a Associação Cultural do Apenado e Egresso (Acuda), há cerca de 20 anos, tem ofertado várias atividades aos presos de Porto Velho, no estado de Rondônia. A Associação disponibiliza a presos do sistema fechado Práticas Integrativas e Complementares em Saúde (Pics), além de oficinas laborais, educacionais, culturais e atividades religiosas e espirituais, visando à reintegração efetiva dessas pessoas à sociedade. Entende-se que a oferta de inclusão social, bem-estar e saúde, tendo as Pics como elemento central, representa uma linha de fuga às estratégias biopolíticas de produção de vidas nuas e de não cidadania. A radicalidade da proposta da Acuda, embora apoiada, em parte, pelo próprio Estado (pois recebe incentivos da Secretaria da Justiça e do Ministério Público), é frequentemente questionada e causa fortes reações contrárias pela sociedade. Por exemplo, o direito de presos participarem de rituais religioso-espirituais utilizando ayahuasca, em Ji-Paraná, foi retirado após as atividades desenvolvidas pela Acuda terem sido mostradas em um programa televisivo de grande audiência. A partir dessa experiência singular, protagonizada pela Acuda, o presente artigo busca discutir como a necropolítica coexiste com a insistência dos presos em viver suas vidas nuas, a partir de fraturas e pontes produzidas no interior das instituições do Estado e daquelas em articulação com ele.

\section{Metodologia}

Este trabalho caracteriza-se como uma pesquisa qualitativa e etnográfica. Esse tipo de pesquisa, segundo Luz (2011), tem contribuído para a construção de conhecimento nas áreas humanas e da saúde proporcionando compreender fenômenos socioculturais dos processos de saúde e doença. A etnografia, para Geertz (1989), produz conhecimento a partir da imersão em um determinado campo de pesquisa, que, segundo Caprara e Landim (2008), precisa ser suficiente para reunir as informações necessárias para compreender determinado fenômeno, a partir da convivência com os sujeitos de pesquisa.

A primeira autora deste trabalho, em uma primeira aproximação, visitou a Acuda em maio de 2016 com o objetivo de conhecer a Associação e pactuar a realização do estudo. Após a anuência da Associação, de ter qualificado o projeto e do aceite do Comitê de Ética em Pesquisa da Universidade, a pesquisadora permaneceu quatro meses em campo (de agosto a dezembro de 2017), onde realizou observações diárias ouvindo presos, familiares, funcionários, voluntários e profissionais da Secretaria de Justiça e de Saúde Prisional do Estado de Rondônia. Além disso, a pesquisadora recebeu de presos algumas das terapias aplicadas na Associação, além de ter se envolvido em outras atividades quando solicitada, como auxiliar na seleção de adolescentes em conflito com a lei para participação em um projeto organizado pela Acuda. No momento da coleta, a Associação contava com cerca de 89 participantes e 69 deles aceitaram participar do estudo, assinando o Termo de Consentimento Livre e Esclarecido (TCLE).

Foram realizadas dez entrevistas em profundidade com presos que se prontificaram a conceder a entrevista, com funcionários e equipe diretiva da Associação. As entrevistas foram gravadas em áudio e posteriormente transcritas. Na transcrição, com a finalidade de não produzir nenhum tipo de julgamento linguístico, todos os relatos utilizados foram colocados na língua portuguesa padrão (Garcez, Bulla, \& Lorder, 2014).

A análise dos dados foi realizada de acordo com o indicado por Angrosino (2009). Primeiramente, os dados dos arquivos eletrônicos e do diário de campo foram organizados. Depois disso foi realizada a leitura panorâmica do material, realizando anotações e destacando partes importantes. Por fim, foram delimitadas categorias ou eixos temáticos em articulação com o referencial teórico adotado.

Todas as observações, impressões, relatos de visitas e das atividades acompanhadas foram registrados no diário de campo que resultou em 
aproximadamente 60 páginas. Os nomes escolhidos para representar os sujeitos de pesquisa são fictícios e foram baseados na sugestão de um deles. Neste texto serão utilizados, principalmente, os relatos de três presos (Saturno, Mercúrio e Apolo) e vinhetas do diário de campo. No Quadro 1, apresentamos algumas características e detalhes sobre as trajetórias desses interlocutores. No Quadro 2, colocamos os excertos das entrevistas e do diário de campo (indicados no corpo do texto com a letra "E" e o número correspondente) utilizados ao longo da apresentação e discussão dos resultados, a seguir.

\section{Quadro 1}

Características gerais e trajetória dos interlocutores.

Saturno: 42 anos, pardo, solteiro, evangélico, nascido na capital de um estado do Nordeste, mas criado em Altamira, no Pará. Estudou até a $4^{a}$ série do ensino fundamental e trabalhava, antes de ser preso, na construção civil. Tinha quatro irmãos: duas irmãs e dois irmãos, além de dois já falecidos. O pai falecera há alguns anos e a mãe era quem o visitava na prisão. Tinha uma filha biológica, que não conhecia, e uma "adotiva" (sic), que era filha de uma ex-companheira. A família mudou para Porto Velho, mas ele foi morar com a irmã mais velha em Curitiba. Foi preso quando retornou a Porto Velho, segundo ele, por tentativa de homicídio. Estava prestes a sair para o regime semiaberto, depois de ficar dois anos no regime fechado. Estava na Acuda há um ano e participou de todas as terapias, fez formação em massagem ayurvédica e estabeleceu-se na oficina de tapeçaria chilena. Disse ter planos de sair da prisão, arrumar uma companheira e voltar a trabalhar na construção civil.

Mercúrio: 27 anos, pardo, evangélico, solteiro, nascido em Manaus, trabalhava como chaveiro de cofres quando foi preso. Com 12 anos, deixou a família para tentar uma "vida melhor" (sic), já que viviam em condições muito precárias. Eram mais dez irmãos e a família vivia do que conseguia produzir. Ao sair de casa, chegou a trabalhar em um navio, mas queria muito voltar a estudar, pois só tinha a $4^{\text {a }}$ série. Como não poderia matricular-se sem a responsabilidade de uma pessoa maior de idade, pediu para um senhor que encontrou na fila da matrícula que o fizesse para ele, explicando a situação. O senhor aceitou e, segundo ele, tornou-se sua família em Porto Velho. Ele o levou para um sítio, onde passou a trabalhar, indo e voltando da cidade todos os dias para estudar. Foi preso, segundo ele, "por ser negro, pobre e por estar próximo de um rapaz que tinha uma pequena quantidade de droga" (sic), negando envolvimento com o tráfico. Já passara por dois presídios de Porto Velho. Estava na Acuda há um ano e passara por todas as terapias, além de ter participado da oficina de tapeçaria de crochê, mas se estabeleceu na oficina de carros. Planejava, ao sair da prisão, poder contar sua experiência no sistema prisional para outras pessoas através de palestras e da escrita de um livro (sobre como se comportar dentro do sistema prisional para conseguir sobreviver). Relatou o desejo de cursar uma faculdade de direito.

Apolo: 32 anos, branco, solteiro, disse não ter religião, mas acreditar em Deus e ler a Bíblia todos os dias. Trabalhava em frigorífico antes de ser preso. Nasceu em Porto Velho, onde sempre residiu. Seus pais eram separados e tinha um irmão e duas irmãs. Cumpria pena há cinco anos e, segundo ele, quando completasse seis poderia ir para o semiaberto. Foi preso por ter cometido crime sexual. Estava na Acuda há quatro anos, participou de todas as terapias e, nas oficinas, realizou formação de massagem ayurvédica, auriculoterapia e Reiki, tendo se estabelecido como auxiliar no consultório odontológico. Cursava zootecnia quando foi preso e disse ter o desejo de, ao sair da prisão, cursar odontologia e de trabalhar no sítio de uma prima em outro estado.

\section{Resultados e discussão}

Tendo em vista o que foi analisado a partir das observações, das entrevistas e do que foi registrado no diário de campo, elaborou-se uma categoria analítica central intitulada: Necropolítica, biopolítica perversa e a subversão do cuidado integrativo: "A prisão é o inferno na terra, Deus nos ACUDA!". Utilizando expressões que eram comuns entre interlocutores do estudo, buscamos discutir como as políticas de Estado diante da situação dos presos se articulam e produzem estratégias mórbidas, biopolíticas, e de que modo convivem com dispositivos que podem promover uma vida florescente para os presos.

Inicialmente, é importante pontuar que a região Norte é uma das regiões mais violentas do Brasil e que essa violência aparece refletida, também, dentro das prisões. Já foram contabilizados vários massacres $\mathrm{e}$ rebeliões, além de denúncias à Corte Interamericana de Direitos Humanos envolvendo as condições de vida dos presos nessa região (Albuquerque Neto, 2017; Barcellos, 2010; Nogueira, 2018; Salla, 2006). De acordo com o Infopen (MJSP, 2017), particularmente em 
Rondônia, havia, em 2016, 10.832 apenados e em Porto Velho, 3.783 presos.

Já a Acuda é uma associação sem fins lucrativos, que visa, segundo seu presidente, ao longo de mais de 20 anos de atuação, promover atividades que auxiliem presos de Porto Velho a serem reintegrados à sociedade. No período em que a coleta foi realizada (de agosto a dezembro de 2017), a Acuda atendeu a mais de 90 presos de três casas prisionais de Porto Velho (Ênio Pinheiro, Aruana e Vale do Guaporé). Segundo informou o Diretor da Associação, que é egresso do sistema prisional e foi um dos primeiros a participar das atividades e terapias, já haviam passado pela Acuda mais de 3 mil presos.

Em uma sede própria, mas dentro do complexo prisional de Porto Velho, a Associação oferecia atividades a presos do sistema fechado (naquele momento havia apenas um participante em regime semiaberto), que se deslocavam algemados, de suas casas prisionais até a Associação, acompanhados por agentes penitenciários, que permaneciam durante todo o dia fazendo a escolta do lado de fora da Acuda. Dentro da Associação não havia agentes e nenhuma pessoa armada fazendo a segurança, apenas câmeras que vigiavam todos os espaços e dois monitores, que eram egressos do sistema prisional e da Acuda e que também auxiliavam nas oficinas.

Praticamente toda a coleta dos dados aconteceu na Associação; de toda forma, era impossível que o sistema prisional não viesse à discussão. Esta era, também, a realidade diária vivida pelos participantes da pesquisa, que retornavam para a prisão no final do dia.

Principalmente no que se refere à vida nas prisões, durante o trabalho de campo foram várias as situações vivenciadas e relatadas pelos presos que denunciavam as estratégias necropolíticas às quais estavam submetidos: falta de condições estruturais, de comida de qualidade e de água potável, falta de assistência, de medicamentos, diversos tipos de violência e as precárias condições de vida anteriores e posteriores ao aprisionamento. Entendemos que uma forma de violência e de tornar alguém vulnerável é não fornecer uma estrutura mínima para que possa manter sua dignidade e sua saúde, como ilustra Saturno (E1).

Quadro 2

Vinhetas ilustrativas da categoria analítica.

\section{Condições estruturais}

E1 - Entre buracos e bichos: Na cela só tinha o colchão, a jega [espécie de cama de cimento], o boi [buraco no chão utilizado como vaso sanitário]. Banheiro lá, se não colocar uma garrafa dessas de refrigerante, a gente pega ela, amarra em cima, e amarra no cano que desce a água e enche ela de água, tampa. No Vale [presídio] tem vasos sanitários, mas no Urso [outro presídio] era só uma espécie de buraco, onde a gente fazia as necessidades, só na massa, bruta mesmo, não era nem queimado. Ali dava muita doença, a gente só tinha cortina de pano. Então, para a gente não ficar com aquele odor, aquele fedor dentro da cela, a gente colocava essa garrafa na boca do cano e encaixava ela, aí não vinha aquele cheiro. Mas se tirava a garrafa, não tinha quem aguentasse. ... Fora o negócio dos tapuru, do corredor. É coisa de louco! Os caras colocavam comida para fora da cela, em umas canaletas, que não eram limpas, ficavam cheias de coisa e ia enchendo de água, ia apodrecendo aquela água e criando tapuru. Aí os bichos vinham pra dentro da cela, ficavam no corredor. É muita coisa ali, Dra. O cara estando preso... Acordava com os tapurus subindo pelos meus braços. Acho que aquele cheiro daqueles bichos jamais sairá do meu nariz, parece que estou sempre fedendo àquilo! (Saturno).

Qualidade da alimentação

E2 - Comida para prejudicar: A comida que vem é muito ruim. Ontem mesmo, o feijão estava azedo! Às vezes vem aberta, você não sabe o que tem lá dentro. Não sei por que, parece que querem prejudicar o preso! Estou há três dias sem conseguir comer (Mercúrio).

\section{Condições da água}

E3 - Água insalubre? Houve uma situação em que várias pessoas, inclusive eu, começamos a passar mal (fortes dores na barriga e diarreia). Percebi que isso começou quando passei a tomar a água que os presos tomavam. Conversando com alguns a respeito da situação, eles relataram que era comum passarem mal por isso, que a água, volta e meia, piorava e muitos passavam mal e que, na prisão, era ainda pior que na Acuda. Ao perguntar a respeito para os responsáveis, na Associação, eles mencionaram que, a princípio, não havia problemas com a água dali, mas que já haviam solicitado à Secretaria uma análise, que nunca foi realizada (Diário de Campo, 18 de setembro de 2017). 
...continuação

Condições de vida pós-aprisionamento

E4 - Emprego na base da cadeia alimentar: Quando sair, quem vai dar oportunidade de emprego para preso? Se há um que nunca foi preso e outro que foi, óbvio que vão escolher o que nunca foi preso. Na cadeia alimentar, o preso está na base de tudo (Mercúrio).

E5 - Ciclo preconceito-retorno ao crime: a culpa é de quem? Eu entendo, professora, que estas pessoas também são vítimas. Não são coitadinhos, todos têm que pagar pelos seus próprios erros, mas será que a própria sociedade não tem culpa por também não dar oportunidade? É o que mais acontece, o cara sai da cadeia e amanhã está de volta. Lá fora o preconceito é muito grande (Mercúrio).

Violência, acesso à saúde e medicação na prisão

E6 - Encobrindo a costela quebrada: Passei mais de seis meses, um ano com a costela quebrada dentro da cadeia e não fui atendido. Porque a polícia, quando chega, não quer saber se tu és bandido, se tu estás certo. Para eles não tem diferença; já chegam batendo, já chegaram batendo muito. Eu cheguei muito machucado, precisando de atendimento médico e não tive. Depois, quando eu tive o atendimento médico, eles escondiam o meu Raio-X, acredito que querendo esconder o fato de ter sofrido violência (Mercúrio).

E7 - Pânico do chaveiro: Mercúrio, logo após meditar, perguntou se poderia conversar comigo. Contou que sentia muito medo, mas que sentiu que poderia conversar comigo, porque eu era psicóloga e ele sabia a respeito do sigilo. Relatou não estar dormindo direito há um bom tempo, não conseguir relaxar ou descansar, tendo perda de peso e cabelo. Sentia-se vigiado o tempo todo por outros presos. Como era chaveiro antes de entrar na prisão, passou a ser disputado pelas facções, mas não queria e não ia entrar como membro em nenhuma, mesmo que isso significasse perder a sua vida. Por sofrer ameaças e não saber o que seria, tinha medo o tempo todo (Diário de Campo, 22 de agosto de 2017).

E8 - Coração comido: Recebi, juntamente com a pedagoga da Associação e, também, por solicitação dela, um preso que estava ingressando na Acuda. A solicitação veio porque as pessoas não o entendiam direito $e$ porque não sabia passar seus dados de identificação e outras informações. Estava bastante abatido e tinha uma cicatriz grande no pescoço que indicava, provavelmente, uma cirurgia. De toda forma, logo descobrimos os motivos de sua desorganização e falta de memória. O irmão dele também estava na Acuda e nos contou que, até bem pouco tempo, ele era um homem "normal e forte", mas que "definhou" após saber que iria ser morto em uma rebelião. Ele foi transferido na noite anterior, mas acabou sabendo que, no seu lugar, um colega de cela havia sido morto e o outro obrigado a comer o coração dele (Diário de Campo, 9 de novembro de 2017).

E9-Apanhar para obedecer: Apolo relata ter apanhado muito ao ser preso e ter ficado com um "buraco" (sic) na cabeça: "Às vezes, ainda sinto muita dor de cabeça. Eles me bateram muito, foram muitos chutes na minha cabeça, fiquei todo roxo e com duas costelas quebradas. . . No início da cadeia sentia muito medo de apanhar de novo, agora estou mais tranquilo, porque eu obedeço" (Apolo).

E10 - Surras fora da lei: O sistema carcerário trata o preso como bicho. Prende, apanha! É isso que nós estamos vivendo! O sistema carcerário é desumano! Eu vi camaradas apanharem nas pernas de ficarem roxas. Roxa, roxa, mesmo assim! Apanharam dos policiais! Colocam todos de cueca, um do lado do outro e pau e pau! Choque, meu irmão?! Eles podem fazer isso? A lei diz que não, diz que tem que resguardar a integridade física do preso. Até hoje eu não entendo. Até onde eu sei, nós somos presos de justiça, somos responsabilidade do Estado. Muitas vezes o preso está batendo o pé dentro da prisão para poder ter um atendimento médico. Se ele diz: "Por favor, me tirem para a enfermaria, por favor!” Tu sabes o que ele vai receber? Vai lá para a frente e ó, peia! Aí o preso volta quietinho, fica uma, duas semanas, quietinho e doente. Pior do que estava (Mercúrio).

E11 - O transporte no(do) inferno: Vi, de longe, Apolo com as mãos nas costas, mancando, com expressão de dor. Aproximei-me dele e perguntei o que havia acontecido. Ele disse que solicitou a escolta porque precisava ir ao banco e foi saltando desde que o camburão começou a andar. Contou que, para fazer o deslocamento, os presos são algemados com as mãos nas costas e colocados soltos lá dentro. Logo, toda vez que o camburão passava por redutores de velocidade ou fazia curvas, ele saltava e caía bruscamente. Disse que estava com muita dor na região no cóccix e que essa situação era comum: a de pedir escolta e voltar machucado. Depois disso, relatou ter ido até a enfermaria da casa prisional para pedir remédio para dor, mas o remédio que lhe foi dado estava com o prazo de validade vencido. Comentou que muitos presos acabam solicitando escolta somente quando não há alternativa, inclusive a escolta da saúde, que era a mesma para todas as situações. Ouvi relatos de muitos que acabavam desistindo de ir ao médico porque diziam voltar piores e machucados, mas que não conseguiam relatar estas situações por medo de represálias (Diário de Campo, 21 de agosto de 2017). 
...continuação

E12 - Me dá um remédio aí: Fora as humilhações com os agentes. A gente chegava lá com dor e pedia um comprimido, daí eles me diziam: “Arruma um para mim aí também!". Daí eu dizia: “Se eu tivesse não estaria te pedindo" (Saturno).

E13 - Emergência pode esperar: Tudo aconteceu por volta das 11h, quando a Acuda solicitou à escolta e ao serviço de emergência. Enquanto esperavam, os colegas tentaram aplicar várias Pics, sem sucesso. Era um clima de bastante preocupação e angústia, já que não havia o que ser feito a não ser ficar tentando contato com os responsáveis. O serviço de emergência chegou para buscá-lo somente cinco horas após solicitado. Justificaram que só havia uma ambulância, mas um dos agentes da escolta deixou escapar, falando baixo e rindo, que estavam só esperando para buscar o corpo. O preso foi levado ao hospital e, depois de três dias internado, retornou para a casa prisional (Diário de campo, 23 de novembro de 2017).

Na perspectiva da biopolítica e da necropolítica, as estratégias do Estado são voltadas para reduzir vidas extremamente precarizadas, vidas nuas, desprovidas de valor, de forma que, por serem tão insignificantes, são passíveis de violência e extermínio, nestes espaços onde impera o Estado de exceção. De acordo com Agamben (2007a), nesse Estado os indivíduos são submetidos a um severo e arbitrário controle que os reduz à "vida nua”, isto é, uma vida limitada a uma existência biológica, sem valor político, situada num espaço onde o direito está permanentemente em suspensão. Isso justifica, por exemplo, as péssimas condições relatadas por Saturno, corroboradas pela Comissão Parlamentar de Inquérito (CPI) que averiguou que é frequente encontrar esgoto correndo nas celas devido à ausência de instalações sanitárias adequadas, além de fezes e urinas armazenadas em garrafas. A referida CPI encontrou vários presídios brasileiros em que havia vasos sanitários sem descarga e que eram utilizados por mais de 70 presos em uma cela, nas quais havia água disponível para limpeza apenas uma vez ao dia. Isso acarreta péssimas condições de higiene, odor insuportável e acúmulo de insetos. Ainda de acordo com a CPI, era comum encontrar celas em que não havia um espaço isolado para o vaso sanitário, sendo este, muitas vezes, apenas um buraco no chão (Câmara dos Deputados, 2009).

A CPI também apontou que é frequente nas prisões brasileiras a péssima qualidade e pouca quantidade da comida servida, quando não é estragada. Em muitos locais é servida em sacos plásticos e os presos comem com as mãos (Câmara dos Deputados, 2009). Muitos frequentadores da Acuda corroboraram a péssima qualidade da alimentação nas prisões, sendo, muitas vezes, impossível comer o que era servido (E2). Nesse sentido, entende-se que a necropolítica opera não apenas na produção direta da morte, mas também para desabilitar e inviabilizar as existências, ou seja, a gestão da morte é operacionalizada pelo abandono e desamparo, naturalizando a condição ilegítima e abjeta de determinadas vidas (Mbembe, 2018).

Além disso, segundo os interlocutores da pesquisa, um dos grandes problemas era a falta de água potável, o que vai ao encontro do que se verifica na maior parte das prisões brasileiras: é frequente não haver acesso à água em quantidades minimamente razoáveis para consumo e higiene (Câmara dos Deputados, 2009). A água disponível não parecia estar apta ao consumo inclusive na Acuda, já que esta se situava na área do complexo prisional da cidade, como foi vivenciado pela pesquisadora no trabalho de campo (E3).

Outra situação importante descrita pelos presos, que coaduna Barcellos (2010), é o fato de que não havia qualquer forma de controle térmico nas celas; no verão, as temperaturas podem chegar por volta dos $50{ }^{\circ} \mathrm{C}$, ou seja, praticamente o inferno mencionado por eles. Estrutura física, alimento digno e água potável seriam o mínimo para que essas pessoas pudessem manter a saúde e privá-las disso é privá-las de um direito pelo qual o Estado é responsável. Privá-las desse mínimo é violentá-las e, de certa forma, inviabilizar suas existências. Ainda, a falta de elementos básicos para sobreviver acaba por incentivar um mercado negro dentro das prisões (Barcellos, 2010).

Destaca-se a continuidade que condições indignas de vida assumem para a população carcerária, seja antes, durante ou depois do encarceramento, como Minayo e Ribeiro (2016) destacam. As autoras apontam que "dentro" e "fora" demarcam as desigualdades e as diferentes condições sociais e formas de se viver, que tornam as pessoas tão diferenciáveis a ponto de terem sua humanidade ignorada. No estudo delas com presos cariocas, verificaram que grande 
parte dos presos nunca se sentiu incluída socialmente e a prisão acaba por aumentar essa sensação de deslocamento, ao encontro do relato de Mercúrio (E4).

Conforme Wacquant (2001), ao deixar a prisão, o indivíduo enfrenta a realidade do desemprego, da desconfiança, do descrédito e do desprezo, restando-lhe poucas alternativas que não o retorno à criminalidade (E5). O autor coloca que este indivíduo fica destinado ao retorno à fome, ao mundo do crime e à prisão, ciclo interrompido somente pela morte. Assim, estima-se que cerca de $70 \%$ dos presos voltem à prisão pela prática de novos crimes (Ipea \& FBSP, 2019). Eles ficam sem acesso a estudo ou qualificação para poder se sustentar, o que aumenta a probabilidade de retornarem à criminalidade e ao sistema (Barcellos, 2010).

A opinião pública almeja que haja prisões mais numerosas e duradouras, não com a ideia de que essas pessoas sejam corrigidas e retornem melhores para o convívio social, mas que a população desviante e perigosa fique reclusa, garantindo a proteção dos demais por tanto mais tempo quanto seja possível (Hilário, 2016). Nessa direção, a necropolítica, para Mbembe (2017, p. 17), remete continuamente à "noção ficcional do inimigo". Segundo Cruz, Minchoni, Matsumoto e Andrade (2017), em nome da defesa social, houve a construção da categoria do suposto inimigo delinquente no Brasil, que é proveniente das camadas populares da sociedade e que se autoriza massacrar. Este inimigo, considerado um "sujeito matável", é semelhante ao que Mbembe (2017) aponta enquanto "escravo contemporâneo". Dessa forma, as estratégias da necropolítica podem justificar a naturalização do extermínio de certos grupos da população, sendo evidente a manifestação da perpetuação do racismo e de manutenção do projeto genocida vinculado à história colonial do Brasil (Pelbart, 2018). Não por acaso, a maior parte dos presos em Porto Velho, como no país, são pretos ou pardos e pobres.

Além das estratégias indiretas de produção da morte e da não cidadania, a necropolítica também opera por meio da violência direta, constituindo um verdadeiro Estado de exceção. Assim, chamou atenção a violência com que os presos de Porto Velho eram tratados: foram várias as situações relatadas e vivenciadas com eles (E6).

Minayo e Ribeiro (2016) assinalam que a violência é um dos maiores agravantes à saúde da população prisional, evidenciando que isso já fazia parte do contexto de vida dessas pessoas antes de serem presas e permanece dentro da prisão. No estudo das autoras, $46,4 \%$ dos homens presos na cidade do Rio de Janeiro disseram sofrer ameaças e ter medo de serem feridos, sofrerem agressões ou serem mortos na cadeia. Para Barcellos (2010), muitas situações de violência nas prisões acontecem pela hiperlotação, pois presos menos periculosos ficam juntos de presos que pertencem a facções criminosas. Para sobreviver, muitas vezes, os primeiros se veem obrigados a integrarem-se às facções e devem seguir ligados a elas mesmo em liberdade, o que retira deles qualquer perspectiva de vida fora do mundo do crime.

Embora as situações envolvendo violência física e psicológica acontecessem tanto entre presos (como as guerras entre facções) quanto entre eles e agentes, os eventos envolvendo as facções eram muito mais extremos. Essa vivência ocasionava, inclusive, repercussões psicológicas importantes, dada a maior dificuldade de afastar-se dos agressores, como evidenciam as vinhetas E7 e E8.

Sobre essas situações, podemos pensar que a biopolítica ou necropolítica convivia com o modo mais antigo de operação do poder: o poder soberano (Foucault, 2009). O soberano é aquele que tem o poder de decidir qual sofrimento causar e que possui o direito sobre a vida do súdito, demonstrando isso por meio de punições bárbaras e exibição pública que servia de exemplo aos outros súditos (Foucault, 2009). Segundo Han (2017), a violência está vinculada ao poder; quanto mais violência, mais poder sobre o outro e, ao matar o inimigo, suplanta-se a morte. Ao matar um preso que faz parte de outra facção, demonstra-se o poder. Mas não basta matar, pois a morte deve ser um espetáculo, como nos tempos mais arcaicos. Assim, se estabelece uma tensão constante que afeta a saúde dos presos, como se vê nos relatos.

Diferentemente da violência entre os presos, a violência policial ou dos agentes era invisibilizada e, de certa forma, permitida e justificada, apesar de ser legalmente proibida, conforme demonstram as vinhetas E9 e E10. Desse modo, o Estado tem o controle dos corpos e as situações de violência são ocasiões adequadas para penetrar e administrar o potencial de vida dos corpos dos grupos populacionais (Kuller \& Gomes, 2018).

Os relatos dos presos desnudavam ainda outro tipo de violência. Além de provocar os ferimentos, negava-se $o$ acesso a medicamentos e a um tratamento 
adequado (E11). A exemplo do constatado por Minayo e Ribeiro (2016), a distribuição de medicamentos era precária ou praticamente inexistente (E12). No estudo das autoras, independentemente da queixa, o remédio prescrito era sempre o mesmo e, quando podiam, os familiares os levavam.

Outra situação envolvendo medicamentos e descaso com a vida dos presos foi presenciada quando um deles ingeriu uma grande quantidade de remédios antidepressivos, passou mal e ficou desmaiado na cozinha da Associação (E13). Achado similar foi descrito por Minayo e Ribeiro (2016), visto que muitos presos entrevistados na pesquisa relataram demora no atendimento em situações de emergência, atentando para o fato de que há falta de ambulâncias e que, assim como em Porto Velho, o transporte dos presos é realizado pela coordenação de segurança, e não pela de saúde. Da mesma forma, houve relatos de maus-tratos no transporte, devido aos quais os presos adiavam os pedidos de atendimento em que tinham que sair da unidade, sendo que muitos denunciaram que já viram outros presos morrerem sem nenhuma assistência (Minayo \& Ribeiro, 2016).

Segundo Barcellos (2010), a violação dos direitos dos presos não é uma exceção, mas uma regra geral, tratando-se de um padrão em todos os estabelecimentos prisionais do país. O tratamento adequado a essas pessoas constitui-se, assim, como exceção. Diante de tantos relatos envolvendo violação de direitos e violência contra os presos, solicitei uma reunião com o Secretário de Justiça do Estado de Rondônia, que agendou uma data para o encontro, mas acabou desmarcando quando já estava a caminho da Secretaria de Justiça. Não houve possibilidade de novo agendamento, o que reitera a invisibilidade que se produz, cotidianamente, no interior das instituições do Estado em relação a tais situações.

Apesar disso, paradoxalmente, ao mesmo tempo que o Estado atua com estratégias necropolíticas, é ele quem ajudava a financiar as práticas promovidas pela Acuda. A maior parte da verba que a Associação utilizava para manter suas atividades vinha de parcerias com a Secretaria de Justiça do Estado, apoiada também por instituições como o Ministério Público. Portanto, o poder e a autoridade do Estado são as principais ameaças aos direitos dos presos, ao mesmo tempo que são essenciais para a efetivação desses direitos.

Dessa forma, além de estratégias biopolíticas e necropolíticas, o Estado se utiliza também de estratégias biopolíticas que entendemos como perversas, tendo em vista que, muitas vezes, acabam somente mascarando sua ampla operação necropolítica. Isso acontece a partir do momento em que o Estado cria leis e políticas de assistência aos presos, mas não cria estratégias para colocá-las efetivamente em prática; quando provê parcos recursos para associações como a Acuda, proporcionando esse tipo de assistência a tão poucos presos, tendo em vista a grande massa carcerária brasileira. Percebe-se, portanto, uma tentativa de encobrir a necropolítica, de forma a também tentar dar conta da pressão de órgãos como a Corte Interamericana de Direitos Humanos, por exemplo.

De toda forma, a Acuda é uma Associação que necessita (e utiliza) dos recursos do Estado para proporcionar as atividades aos presos, tendo que mediar todas as instâncias, sob constante ameaça de ter suas atividades suspensas por tratar desses indivíduos como "pessoas" (sic). Porém, a Associação tem tentado agir de forma a subverter essas situações.

Assim como a prisão foi apontada por alguns presos como o "inferno na terra" (sic), a Acuda era colocada por muitos dos participantes como um espaço de acolhimento e de "salvação" (sic). Ouvi a expressão "Deus nos ACUDA!", que faz referência à Associação como um lugar de fuga possível e de acesso a formas de cuidado, liberdade e de (re)existência. Era visível, nas observações, que ela proporcionava uma forma muito diferente de tratamento, pois visava a um cuidado integral do indivíduo, proporcionando cuidados em saúde, educação, formação profissional, assistência espiritual-religiosa, reinserção social e familiar. Entendemos aqui o cuidado integral como um conjunto de ações que devem ser integradas ao ser humano, para proporcionar o desenvolvimento de capacidades desenvolvidas nas relações interpessoais, em seu contexto, considerando as necessidades do indivíduo-sujeito-cidadão (Ferraz, Silva, Silva, Reibnitz, \& Backes, 2005; Hollenberg, 2006).

Tendo em vista sua organização e funcionamento, percebeu-se seu caráter de instituição disciplinar, que se utilizava de formas de controle diferentes daquelas utilizadas nas prisões. A disciplina objetivava extrair e maximizar forças por meio do trabalho e do monitoramento constante (Foucault, 2005), mas não ter nenhum tipo de armamento ou policial dentro dos muros da Associação parece-nos uma forma de subversão ao sistema, que se utiliza, na maior parte das vezes, da violência física e da opressão. 
Observamos na Acuda tanto a atuação do poder disciplinar quanto de estratégias de biopoder. Trata-se de um trabalho sobre os corpos para torná-los dóceis e, também, para torná-los aptos a viverem novamente em sociedade, de acordo com as normativas sociais. É o biopoder que vai ser o responsável por inserir os corpos no aparelho de produção, ajustando-os aos processos econômicos (Foucault, 2015, p. 152). De toda forma, essa atuação também pode ser entendida como uma negociação entre a Acuda e o Estado, que é quem financia seu trabalho.

Mas chamou-nos a atenção a maneira como a Acuda tentava subverter, de muitas maneiras, as ações necropolíticas. Uma forma preponderante de subversão era fornecer tanto o acesso às Pics que são práticas de saúde não biomédicas que apontam para a integralidade do cuidado (Luz, 2005) quanto a formação nelas. Assim, parece afrontoso possibilitar que presos recebam massagens, por exemplo, e que essa possa vir a ser uma ferramenta de trabalho ao saírem da prisão, já que vários deles mencionaram o desejo de seguirem suas trajetórias como terapeutas.

Outra forma de subversão tem sido possibilitar aos presos "saídas" das prisões, seja para irem à Associação, para alguns participantes irem à Casa Sentenciada ofertar práticas de cuidado aos adolescentes (fornecendo modelos e reabilitação para eles), seja para alguns deles irem para Ji-Paraná participar de rituais utilizando ayahuasca. Várias vezes pude observar presos na frente da Associação, sem nenhum tipo de algema, nem sob a mira de armas, buscando coisas na rua (que tinham a ver com o trabalho que desenvolviam) ou esperando o transporte para levá-los a outros lugares. Ao proporcionar esse tipo de confiança e de liberdade aos presos (mesmo que assistida), a Acuda também recebia confiança em troca e os presos, pelo menos até aquele momento, perdiam o interesse em fugir, já que praticamente inexistiam fugas ou tentativas de fugas da Associação.

Assim, as atividades desenvolvidas na Acuda puderam ser analisadas sob duas óticas que não eram contraditórias: a de fornecer aos presos ferramentas para controlá-los e, também, fornecer uma forma de cuidado e saúde, que era a única a que muitos presos tinham acesso e que nos pareceu, em muitas circunstâncias, fornecer subsídios para auxiliar na mudança de suas trajetórias. Nesse sentido, Foucault aponta que há duas séries: a série desenvolvida por instituições, que envolve o corpo, o organismo e a disciplina; e a série desenvolvida pelo Estado, que envolve as populações, os processos biológicos e os mecanismos de regulamentação. $\mathrm{O}$ autor coloca que não há, necessariamente, oposição entre instituição e Estado, já que uma dimensão pode interpenetrar a outra, articulando-se (Foucault, 2005). Neste caso, podemos pensar que a Acuda também servia ao Estado, na medida em que ele financiava e fiscalizava suas atividades.

\section{Considerações finais}

Como foi analisado com base nos dados coletados em Porto Velho, principalmente do que foi observado, vivenciado e a partir dos relatos de Saturno, Mercúrio e Apolo, percebemos que os presos estão submetidos, dentro das prisões, às estratégias da necropolítica e também de uma biopolítica que tratamos aqui como perversa, por ser o Estado tanto aquele que violenta quanto aquele que, de uma forma precária, protege e provê recursos.

A Acuda se insere naquilo que o poder disciplinar e a biopolítica priorizam: as estratégias para a manutenção da vida e de uma vida útil. As formas de cuidado integrativas ofertadas aos presos contrariam a lógica necropolítica e, por isso, a realização do trabalho da Associação torna-se tão difícil e encontra tantas barreiras. A Acuda acaba, em muitas circunstâncias, subvertendo essa lógica e, por isso, vive sob constante ameaça.

Ao sair dos muros da Acuda, os presos acabam enfrentando o estigma da prisão em uma sociedade que os repele. Fora dos muros da Associação, essas vidas são indesejáveis - seja nas prisões, seja no retorno à sociedade. Talvez isso justifique o fato de que muitos desejam permanecer na Associação mesmo após saírem da prisão (e muitos, de fato, permanecem). Somente ali, talvez, eles tenham um lugar de existência possível até então.

Mesmo submetidos a tantas estratégias de poder sobre a vida e sobre a morte, é interessante perceber que Saturno, Mercúrio e Apolo fazem planos tão esperançosos (e alguns ambiciosos) para seus futuros. O desejo de mudança, de continuar suas trajetórias ao lado de suas famílias e de (re)existir acaba encontrando brechas que possivelmente tenham despertado a partir do cuidado recebido na Associação.

Entendemos que o cenário mortífero e recrudescente das atuais políticas públicas e macroeconô- 
micas no país atingem principalmente as minorias, ameaçadas por uma necropolítica que é, pode-se dizer, generalizada. Num contexto como o das prisões brasileiras, historicamente calcadas na exclusão e na (co)produção de não cidadãos, é importante compreender que experiências de resistência e subversão, como as ilustradas pela Acuda, podem se constituir como alternativas, ainda que no interior das instituições operadoras de estratégias necropolíticas.
Destaca-se, a importância de novos estudos sobre a temática abordada neste artigo, principalmente explorando as estratégias da biopolítica perversa. Outras investigações poderiam agregar as perspectivas de presos que não tiveram acesso à Associação e, também, entrevistas e observações dentro das prisões, investigando suas possíveis repercussões, assim como outras formas de operação da biopolítica perversa no interior dos presídios.

\section{Referências}

Adorno, S. (1991). A prisão sob a ótica de seus protagonistas. Itinerário de uma Pesquisa. Tempo Social, 3(1-2), 7-40. https:// doi.org/10.1590/ts.v3i1/2.84813

Agamben, G. (2007a). Estado de exceção. Boitempo Editorial.

Agamben, G. (2007b). Homo Sacer: O poder soberano e a vida nua. UFMG.

Albuquerque Neto, F. de S. C. de. (2017). Prisões e o trabalho forçado no Brasil na segunda metade do século XIX. Passagens: Revista Internacional de História Política e Cultura Jurídica, 9(1), 40-57.

Angrosino, M. (2009). Etnografia e observação participante. Artmed.

Barcellos, A. P. de. (2010). Violência urbana, condições das prisões e dignidade humana. Revista de Direito Administrativo, 254, 39-65. https://doi.org/10.12660/rda.v254.2010.8074

Bello Ramírez, J. A., \& Parra Gallego, G. (2016). Cárceles de la muerte: Necropolítica y sistema carcelario en Colombia. Universitas Humanística, (82), 365-391. http://www.redalyc.org/articulo.oa?id=79145845014

Câmara dos Deputados. (2009). Comissão Parlamentar de Inquérito do Sistema Carcerário. bd.camara.gov.br/ $\mathrm{bd} /$ handle/bdcamara/2701

Caprara, A., \& Landim, L. P. (2008). Etnografia: Uso, potencialidades e limites na pesquisa em saúde. Interface, 12(25), 363-376. https://doi.org/10.1590/S1414-32832008000200011

Cruz, A. V. H., Minchoni, T., Matsumoto, A. E., \& Andrade, S. S. de. (2017). A ditadura que se perpetua: Direitos humanos e a militarização da questão social. Psicologia: Ciência e Profissão, 37(n. spe.), 239-252. https://doi.org/ $10.1590 / 1982-3703180002017$

Ferraz, F, Silva, L. W. S. da, Silva, L. A. A. da, Reibnitz, K. S., \& Backes, V. M. S. (2005). Cuidar-educando em enfermagem: Passaporte para o aprender/educar/cuidar em saúde. Revista Brasileira de Enfermagem, 58(5), 607-610. https:// doi.org/10.1590/S0034-71672005000500020

Foucault, M. (2005). Em defesa da sociedade. Curso dado no Collège de France (1975-1976). Martins Fontes.

Foucault, M. (2009). Vigiar e punir: Nascimento da prisão (R. Ramalhete, Trad.; 37a ed.). Vozes.

Foucault, M. (2015). Microfisica do poder (R. Machado, Trad.; 2a ed.). Paz e Terra.

Garcez, P. de M., Bulla, G. da S., \& Loder, L. L. (2014). Práticas de pesquisa microetnográfica: Geração, segmentação e transcrição de dados audiovisuais como procedimentos analíticos plenos. Delta, 30(2), 257-288. https:// doi.org/10.1590/0102-445078307364908145

Geertz, C. (1989). A interpretação das culturas. Livros Técnicos e Científicos.

Han, B.-C. (2017). Topologia da violência (E. P. Giachini, Trad.). Vozes.

Hilário, L. C. (2016). Da biopolítica à necropolítica:Variações foucaultianas na periferia do capitalismo. Sapere aude, 7(13), 194-210. https://doi.org/10.5752/P.2177-6342.2016v7n13p194

Hollenberg, D. (2006). Uncharted ground: Patterns of professional interaction among complementary/alternative and biomedical practitioners in integrative health care settings. Social Science \& Medicine, 62(3), 731-744. https://doi.org/10.1016/j.socscimed.2005.06.030 
Instituto de Pesquisa Econômica Aplicada \& Fórum Brasileiro de Segurança Pública. (2019). Atlas da Violência 2019.

Kuller, L. F., \& Gomes, M. (2018). Enquadramentos diferenciais de violência: Uma análise das audiências de custódia em São Paulo. Ambivalências, 6(12), 153-177. https://www.researchgate.net/publication/330874491_ Enquadramentos_diferenciais_de_violencia_Uma_analise_das_audiencias_de_custodia_em_Sao_Paulo

Luz, M. T. (2005). Fragilidade social e busca de cuidado na sociedade civil de hoje. In R. Pinheiro \& R. A. Mattos (Orgs.), Cuidado: As fronteiras da integralidade (pp. 9-20). IMS/UERJ; Cepesc; Abrasco.

Luz, M. T. (2011). Especificidade da contribuição dos saberes e práticas das Ciências Sociais e Humanas para a saúde. Saúde \& Sociedade, 20(1), 22-31. https://doi.org/10.1590/S0104-12902011000100004

Mbembe, A. (2017). Políticas da inimizade. Antígona.

Mbembe, A. (2018). Necropolítica (3a ed.). N-1 Edições.

Minayo, M. C. de S., \& Constantino, P. (Orgs.). (2015). Deserdados sociais: Condições de vida e saúde dos presos do estado do Rio de Janeiro. Fiocruz.

Minayo, M. C. de S., \& Ribeiro, A. P. (2016). Condições de saúde dos presos do estado do Rio de Janeiro, Brasil. Ciência \& Saúde Coletiva, 21(7), 2031-2040. https://doi.org/10.1590/1413-81232015217.08552016

Ministério da Justiça e Segurança Pública. (2017). Levantamento Nacional de Informações Penitenciárias.

Nogueira, E. (2018). O sistema penitenciário de Rondônia: Panorama atual e perspectivas [Monografia, Graduação em Direito, Centro Universitário São Lucas].

Pelbart, P. P. (2018). Necropolítica tropical: Fragmentos de um pesadelo em curso. N-1 Edições.

Salla, F. (2006). As rebeliões nas prisões: Novos significados a partir da experiência brasileira. Sociologias, 8(16), 274-307. http://www.scielo.br/pdf/soc/n16/alln16.pdf

Wacquant, L. (2001). As prisões da miséria. Jorge Zahar.

Wacquant, L. (2007). Punir os pobres: A nova gestão da miséria nos EUA [A onda punitiva] (S. Lamarão, Trad.; 3a ed.). Revan.

Wacquant, L. (2008). O lugar da prisão na nova administração da pobreza (P. Miraglia e H. de Mello Filho, Trads.). Novos Estudos, (80), 9-19. https://doi.org/10.1590/S0101-33002008000100002

\section{Marisangela Spolaôr Lena}

Psicóloga graduada pela Universidade Federal de Santa Maria (UFSM), Santa Maria - RS, Brasil. Mestre em Psicologia pelo Programa de Pós-graduação em Psicologia da UFSM; realizou mobilidade acadêmica na Faculdade de Psicologia e Ciências da Educação da Universidade do Porto, Porto, Portugal. Doutora em Saúde Coletiva pelo Programa de Pós-Graduação em Saúde Coletiva na Universidade do Vale do Rio dos Sinos (Unisinos), São Leopoldo - RS, Brasil. Realiza investigação em: Promoção da Saúde; Cuidado integrativo; Práticas Integrativas e Complementares em Saúde; Sistema Prisional; Direitos Humanos; Violência; Necropolítica e Biopolítica.

E-mail: marisangelaslena@gmail.com

(1) https://orcid.org/0000-0002-0053-7954

\section{Tonantzin Ribeiro Gonçalves}

Doutora em Psicologia pela Universidade Federal do Rio Grande do Sul (UFRS), Porto Alegre - RS, Brasil. Professora nos Programas de Pós-Graduação em Saúde Coletiva e em Psicologia da Universidade do Vale do Rio dos Sinos (Unisinos), São Leopoldo - RS, Brasil.

E-mail: tonanrib@yahoo.com.br

(1) https://orcid.org/0000-0003-0249-3358

Endereço para envio de correspondência:

Universidade do Vale do Rio dos Sinos. Av. Unisinos, 950, Escola de Saúde, Cristo Rei. CEP: 93022-750. São Leopoldo - RS. Brasil. 
Recebido 10/02/2020

Aceito 19/07/2021

Received 02/10/2020

Approved 07/19/2021

Recibido 10/02/2020

Aceptado 19/07/2021

Como citar: Lena, M. S., \& Gonçalves, T. R. (2022). Necropolítica, biopolítica perversa e a subversão do cuidado integrativo para presos. Psicologia: Ciência e Profissão, 42, 1-13. https://doi.org/10.1590/1982-3703003233902

How to cite: Lena, M. S., \& Gonçalves, T. R. (2022). Necropolitics, perverse biopolitics, and the subversion of the integrative care for prisoners. Psicologia: Ciência e Profissão, 42, 1-13. https://doi.org/10.1590/1982-3703003233902

Cómo citar: Lena, M. S., \& Gonçalves, T. R. (2022). Necropolítica, biopolítica perversa y subversión de la atención integral a los prisioneros. Psicologia: Ciência e Profissão, 42, 1-13. https://doi.org/10.1590/1982-3703003233902 